\title{
Rauman seudun murteen sisäheitosta
}

Heikki Ojansuun mukaan sisäheittoa esiintyy lounaismurteissa seuraavasti: sanansisäisen vokaalin heittymistä tavataan — varsinkin paikannimistössä - jossakin määrin kautta koko Lounais-Suomen, mutta säännöllisimmin vokaali on kuitenkin heittynyt Rauman seudun kansankielessä, nimenomaan Eurajoen, Lapin, Rauman, Pyhänmaan, Laitilan, Hinnerjoen ja (osaksi) Uudenkirkon (nyk. Kalannin) murteessa. Tutkijan mukaan tämän alueen sisäheitto noudattaa seuraavaa sääntöä: "Sisäheitto on säännöllisesti tapahtunut [kolmitai useampitavuisen] ${ }^{1}$ sanan toisessa tavussa, milloin ensi tavu on ollut pitkä, toinen [alkuperäisesti] lyhyt ja kolmannen tavun alussa on ollut joku puheäänellisistä konsonanteista $l, m, n, r, v$ " (Ojansuu I, 115-116) ${ }^{2}$.

Myöhemmät tutkijat ovat puolestaan käsitellessään sisäheittoa

${ }^{1}$ Hakusulkuihin sijoittamani tarkennukset ovat omiani.

${ }^{2}$ Käytän tässä artikkelissa esiintyvistä tekstilähteistä sekä muusta keskeisestä kirjallisuudesta lyhenteitä seuraavasti:

Hahnsson $\mathrm{I}=$ J. A. Hahnsson, Muoto-opillinen selitys Eurajoen, Lapin, Rauman, Pyhänmaan, Laitilan ja Uudenkirkon pitäjien kielestä. I. Ääni-oppi. Suomi, toinen jakso, 6. osa. Helsinki 1866.

Hahnsson II $=$ J. A. Hahnsson, Muoto-opillinen selitys Eurajoen, Lapin, Rauman, Pyhänmaan, Laitilan ja Uudenkirkon pitäjien kielestä. II. Muoto-oppi. Suomi, toinen jakso, 7. osa. Helsinki 1868.

Ikola-Wiik = Osmo Ikola ja Kalevi Wiik, Eurajoen murretta. Kansankielen näytteitä 4. Sananjalka 8. Turku 1966.

Kettunen I = Lauri Kettunen, Suomen murteet. I. Murrenäytteitä. Helsinki 1930.

Kettunen II = Lauri Kettunen, Suomen murteet. II. Murrealueet. Helsinki 1930. Ojansuu I = Heikki Ojansuu, Suomen lounaismurteiden äännehistoria. Vokaalioppi. Suomi, kolmas jakso, 19. osa. Helsinki 1901.

Ojansuu II = Heikki Ojansuu, Suomen lounaismurteiden äännehistoria. Konsonantit. Suomi, neljäs jakso, 2, osa. Helsinki 1904. 
omissa suomen murteiden yleisesityksissään paljolti nojautuneet tähän määritelmään. Niinpä v. 1945 monistetuissa Martti Rapolan suomen äännehistorian luennoissa on sisällöllisesti täsmälleen Ojansuun määritelmää vastaava sääntö (Rapola I, 225); v. 1966 ilmestyneestä äännehistorian painetusta laitoksesta puuttuu kuitenkin maininta siitä, että sisäheiton edellytyksenä olisi toisen tavun lyhyys (Rapola II, 486). V. 1930 julkaisemassaan suomen murteiden yleisesityksessä Lauri Kettunen ei puolestaan mainitse Ojansuun esittämää kolmannen tavun alkuäänteen asettamaa rajoitusta (Kettunen II, 2). On kuitenkin mitä ilmeisintä, että sisäheittoa koskeva sääntö on tarkoituksenmukaisin Ojansuun mainitsemassa muodossa. Niinpä sisäheitto on tapahtunut poikkeuksellisen harvoin esim. $i$-loppuisen diftongin sisältävässä tavussa (ks. näiden diftongien käsittelyä esim. teoksesta Ojansuu I, 199-234) eikä koskaan esim. tavussa, jota seuraa vokaalilla alkava tavu.

Vaikka Rauman seudun murteen sisäheitosta annettuun määritelmään on usein Ojansuusta lähtien sisällytetty sana "säännöllisesti", ei sääntö itse asiassa liene ollut siteeratussa muodossaan koskaan ehdottoman pitävä. Ensinnäkin esiintyy ainakin Ojansuun aikojen jälkeen tältä alueelta litteroiduissa parhaidenkin puhujien näytteissä melkoista horjuntaa; sama tai aivan samanlainen muoto esiintyy toisella kertaa sisäheittoisena, toisella taas sanansisäisen vokaalinsa säi-

Rapola $\mathrm{I}=$ Martti Rapola, Suomen kielen äännehistorian luentojen pääkohdat. Moniste. Helsinki 1945.

Rapola II = Martti Rapola, Suomen kielen äännehistorian luennot. Helsinki 1966. Ruoppila-Soutkari = Veikko Ruoppila ja Pentti Soutkari, Suomalainen murrelukemisto. Helsinki 1959.

SKMK = Suomen kansan murrekirja. Länsimurteet. 2. painos. Porvoo 1953.

Virtaranta-Soutkari $=$ Pertti Virtaranta--Pentti Soutkari, Näytteitä suomen murteista. Helsinki 1964.

Luettelossa mainituista kielennäytteitä sisältävistä teoksista olen käynyt läpi tekstit, jotka on merkitty muistiin Ojansuun mainitsemista pitäjänmurteista (ks. artikkelini alkua). Lisäksi olen Iukenut teoksesta Pertti Virtaranta, Suomen kansa muistelee (Porvoo 1964) Pyhänmaan murteesta merkityn kielennäytteen, mutta siinä on epäodotuksenmukaisia sisäheitottomia muotoja niin paljon, ettei näytteestä ole kannattanut poimia esimerkkejä. Samasta syystä olen jättänyt eräät Turun Yliopiston suomen kielen laitoksessa olevat, vielä julkaisemattomat murrenäytteet artikkelissani huomiotta.

Eräiden murre-esimerkkien kirjoitusasua on jonkin verran karkeistettu, 
lyttäneenä, esim. kah $\delta$ e $\eta$ G $\ddot{u} m n$ e markay Gultarahaki (IkolaWiik, 207:38-208:1, Euraj.), k a h $\delta$ e $\eta$ G üm m e n e marka rahast (Ikola-Wiik, 208:11, Euraj.); kon Deit_olis pundaril pähä

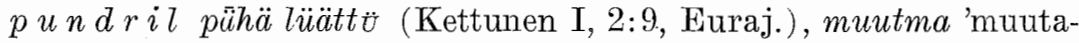
mat' (SKMK, 10, Lappi), muutamis (SKMK, 11, Lappi) jne. Ilmeisesti tällaista horjuntaa on ainakin osassa murrealuetta ollut jo aikaisemminkin. Niinpä Hahnsson mainitsee esim., että uri, yri -loppuisissa sanoissa voi Laitilassa toisinaan olla vartalon vokaali säilyneenä, muodon nylkrit 'nylkyriä' rinnalla esiintyy näet myös asu nylkyrit 'id.' (Hahnsson I, 20). Toisaalla tutkimuksessaan hänellä taas on rinnakkain laitilalainen muoto roiklette' 'roikaleitten' ja Uudenkirkon murteinen muoto roikalette' (Hahnsson II, 318) jne.

Toiseksi esiintyy teksteissä joitakin tapauksia, joissa sisäheitto näyttää levinneen yli säännöissä mainittujen rajojen. Niinpä muodossa semne (Ojansuu I, $119^{3}$; Tkola - Wiik, 206:23, Euraj.) on sisäheitto tarkasteltavassa murteessa melko yleisesti tapahtunut, vaikka toinen tavu ei olekaan alkuperäisesti lyhyt. Muodoissa semsses (Ojansuu I, 119) ja semssen (Ikola-Wiik, 207:4, Euraj.) on toinen tavu ollut alkuperäisesti pitkä ja sitä paitsi kolmatta tavua on alkanut soinniton konsonantti (tällaisista muodoista enemmän tuonnempana, ks. kohta 5). Samoin esim. marjannimissä manskaine, mustkaine, juamkaine jne., jotka Ojansuu mainitsee kuulleensa Uudellakirkoilla, Laitilassa ja Pyhässämaassa sisäheittoisina (Ojansuu I, 121), on ko]mannen tavun alussa ollut soinniton konsonantti. Muodoissa latna 'latinaa' tai Kahril 'Kaharille' (Ojansuu I, 121) vihdoin ensimmäinen tavu ei ole ollut pitkä.

Kolmanneksi on vihdoin jo Hahnssonin ja Ojansuun ajoista saakka ollut olemassa melko runsaasti sellaisia muotoja, joissa olisi olemassa yleiset sisäheiton edellytykset, mutta joissa kuitenkin sanansisäinen vokaali joko aivan poikkeuksettomasti tai ainakin suhteellisen säännöllisesti on säilyneenä. Nämä tapaukset ovat tässä artikkelissa ensisijaisen huomion kohteena.

Uusimmassa suomen murteiden yleisesityksessä, Rapolan äännehistorian painetuissa luennoissa, sanotaan näistä "säännöllisistä poik-

${ }^{3}$ Useimmat Ojansuun esimerkit, joiden yhteydessä ei ole merkintää siitä, minkä pitäjän murretta ne edustavat, lienevät Eurajoelta (ks. Ojansuu I, 116). 
keuksista" seuraavaa: "Tasoituksista johtuu, että toisinaan ei sisäheittoa näyttäisi tapahtuneen, esim. anDamaha, kittämine, taitamattomast, nukkunu (vrt. juapnu), taitavast. Nämä kuuluvat suuriin muotoryhmiin, joissa vartalovokaali on lyhyen ensi tavun jäljessä äännelaillisesti säilynyt; niistä on analogia lähtenyt." (Rapola II, 486-487). Niinä suurina muotoryhminä, joihin Rapola mitä ilmeisimmin viittaa, luettelee Ojansuun lounaismurteiden äännehistoria seuraavat:

1. nut, nüt -loppuiset akt. II partis:n muodot. Ojansuun mukaan sanotaan säännöllisesti nukkunu, hualinu jne. Vain substantiivisesti käytetyn ja siis paradigmastaan kokonaan irronneen juapnu-sanan esim. juaṕnuy kans (Euraj.), juapnuit (Rauma) - Ojansuu mainitsee kuulleensa sisäheittoisena (Ojansuu I, 118). Läpikäymissäni murreteksteissä sanansisäinen vokaali on poikkeuksettomasti säilyneenä, esim. koettanu $\breve{k} k a$ (Ikola-Wiik, 196:38, Euraj.), joutunus (Kettunen I, 1:8, Euraj.), maksanun (SKMK 16, Laitila).

2. III:n ja IV:n inf:n muodot. Ojansuun mukaan sanotaan säännöllisesti esim. anDamaha, kìttämäst, jałsamine jne. (Ojansuu I, 117-118). Ojansuu ei missään sano - eikä myöskään hänen esimerkeistään käy ilmi —, sisällyttäälkö hän tähän ryhmään myös minenloppuiset verbaalisubstantiivit, jotka muotonsa puolesta ovat identtiset IV inf:n muotojen kanssa. Myös nämä varsin lukuisasti nykyisissä murreteksteissä esiintyvät muodot ovat joka tapauksessa poikkeuksettomasti sisäheitottomia. ${ }^{4}$ Muutamia esimerkkejä läpikäymistäni teksteistä: hautomas, paistamas (Ruoppila-Soutkari, 10:20, Laitila), naoramanki 'nauramaankin' (SKMK, 13, Hinnerj.), on Gaevet $k$ a e vamistas (Ikola-Wiik, 196:9, Euraj.), tul äkki lähtemine (Kettunen I, 2:3, Euraj.).

Ojansuu ei teoksessaan puhu mitään ns. agenttipartisiippien sisäheittoisuudesta tai sisäheitottomuudesta; joka tapauksessa taivutettu agentitipartisiippi on täysin III inf:n muotojen kaltainen. Myöskään kielennäytteissä ei ole esiintynyt varsinaisia $m a$, mä -tunnuksisia partisiippeja. Mutta sitä vastoin olen tavannut niistä agenttipartisiipin kaltaisia substantiiveja sekä yhden "yhdyssanan", jonka alku-

${ }^{4}$ Pyhänmaan tekstissä esiintynyt muoto kärejän $k \ddot{a} y m n$ en ei ole lainkaan tähän yhteyteen, vaan kohtaan 5 kuuluva sisäheittomuoto. 
osana esiintyy agenttipartisiipin kaltainen muoto; myöskään niistä ei ole yhdestäkään vokaali ollut heittyneenä, esim.: Jälkke isän $k u a$ le ma (SKMK, 14, Hinnerj.), keväst ennen käen $k u k k u m a$ (SKMK, 12, Lappi), a m $p$ u $m$ a aset (Kettunen I, 1:9, Euraj.).

Ojansuulla on teoksessaan erillisenä poikkeusryhmänä maton, mätön -loppuiset karitiiviadjektiivit. Koska nämä ovat edellä käsitellyistä muodoista edelleen johdetut, voitaneen ne kuitenkin hyvin yhdistää niihin. Ojansuun mukaan murteessa esiintyvät muodot ovat "säännöllisesti" sisäheitottomia, kuten esim. muoto taitamattomast. Tutkija mainitsee tavanneensa vain yhden sisäheittoisen tähän yhteyteen kuuluvan muodon, nimittäin Eurajoella partitiivin opmattomi. (Ojansuu I, 118.) Tarkastamissani kielennäytteissä on ollut yksi ainoa tähän kuuluva muoto; se on sisäheitoton. Se sattuu olemaan sama johdannainen, jonka Ojansuu oli kuullut sisäheittoisena: Laitilan murteen tekstissä on näet muoto oppemattomat (SKMK, 16).

3. Niissä poikkeustapauksissa, joissa kolmannen tavun alkajana on kysymykseen tulevista konsonanteista $v$, Ojansuu tyytyy ylimalkaiseen toteamukseen: "Tasoituksesta riippuu, että nykyään sanotaan aina auttava, anDava, taitavast j.n.e." (Ojansuu I, 121). Ensimmäisistä esimerkeistä ei näy, onko niitä käytetty finiittisesti vai infinịittisesti; mahdollisesti hän on esimerkeillään tarkoittanut sekä mon. 3. pers:n että I partis:n muotoja. Joka tapauksessa jälleen ainakin myöhempien tekstien mukaan niin mainituissa persoona- kuin infiniittimuodoissa vokaali on jokseenkin säännöllisesti säilyneenä ${ }^{5}$, esim. uisiva 'uivat' (Kettunen I, 6:2, Rauma), hänen o jollantavals $s \bar{a} t a$ $v i$ (Ikola-Wiik, 195:19, Euraj.), kiahuva vet (VirtarantaSoutkari, 13, Euraj.).

Kielennäytteiden mukaan ovat sisäheitottomia myös tällaisten $v a$, $v \ddot{a}$-muotojen inen-loppuiset johdannaiset, esim. kaikilt $k u l k$ e $v a i$ silt (SKMK, 12, Lappi), Stä py ärtyväist aikka [= aikaa, jolloin kaatumatautinen sai kohtauksia] (SKMK, 13, Hinnerj.).

4. Ne komitatiivi- ja essiivimuodot, joihin on liittyneenä suf-

${ }^{5}$ Vain yhden ainoan sisäheittoisen muodon olen teksteistä tavannut. Se esiintyy tyypillisimpään sisäheittoalueeseen vain osittain kuuluvan (ks. artikkelini alkua) Kalannin murteessa. Muoto on olvannas (SKMK, 22), ja se on siis myös sikäli poikkeuksellinen, että siinä ei pitäisi ensimmäisen tavun lyhyydenkään vuoksi esiintyä sisäheittoa. 
fiksi. Näistä Ojansuu sanoo: "...kesknäs<keskenänsä [on] ainoa sisäheittoinen essiivimuoto, minkä olen merkinnyt; komitatiiveja ei ole kokoelmissani" (Ojansuu I, 119). Ojansuun sanonta on tässä kohden jonkin verran hämärä. Se tuntuisi kuitenkin viittaavan siihen, että hän joka tapauksessa on merkinnyt ainakin sisäheitottomia essiivimuotoja. Mutta eikö hän siis ole lainkaan merkinnyt murteesta tähän yhteyteen kuuluvia enempää sisäheitottomia kuin -heittoisia komitatiiveja? Miksi hän sitten kuitenkin on sijoittanut komitatiivit essiivien kanssa yhteen sisäheittoilmiön poikkeusryhmäksi, varsinkin kun hän vielä viittaa Hahnssonin tutkimuksessaan Raumalta ja Eurajoelta esittämiin sisäheittoisiin komitatiiveihin kenknes 'kenkineen', leipnes 'leipineen', päivnes 'päivineen', sukknes 'sukkineen' (Hahnsson II, 272)?

Epäilemättä tämän kohdan esimerkistöä on ollut omiaan suuresti monimutkaistamaan se seikka, että komitatiivin ja essiivin päätteessä esiintyy käsiteltävässä murteessa laajalti geminaatta $n n$, esim. lehtinnes, nuarennakki (ks. esim. Ojansuu II, 148-149, Hahnsson II, 62). Hahnssonin mukaan tällaisia geminaatallisia muotoja esiintyy ennen kaikkea Eurajoen, Rauman ja Lapin murteissa. Laitilan rajalla tunnetaan viimeksi mainitussa pitäjässä kuitenkin myös yksinäis- $n: n$ sisältävät päätteet, esim. lehmänäs 'lehmänänsä', lehmines 'lehminensä', piikanas 'piikanansa' (Hahnsson I, 62). Kuten esimerkeistäkin näkyy, ovat täältä merkityt muodot sisäheitottomia.

nn:llisiä muotoja esiintyy myös kielennäytteissä - esim. tykönnäs, kotonnas (SKMK, 11, Lappi) 一, mutta samoin myös muutamia tähän yhteyteen kuuluvia yksinäis-n:llisiä muotoja. Sisäheittoisena on esiintynyt essiivi kesknäs (Ikola-Wiik, 207:2, Euraj.), siis sama muoto, jonka Ojansuukin on merkinnyt. Sisäheitottomina sitä vastoin ovat esiintyneet muodot päivines (Ikola-Wiik, 211:33, Euraj.) ja yntänäs 'kauttaaltaan' (SKMK, 15, Laitila).

5. Vihdoin Ojansuu mainitsee kuulleensa vain harvoja sellaisia sisäheittoisia nen-loppuisia muotoja, joissa loppua edeltää $i$-vokaali. Eurajoen murteesta hän ilmoittaa kuitenkin merkinneensä muodon vastonkä̈̈mne ja Lapista muodot sünDne ihmne. nen-loppuisia muotoja käsitellessään Ojansuu joutuu kuitenkin toteamaan tavanneensa nimenomaan tässä ryhmässä koko joukon myös toisenlaista poikkeavuutta yleisistä sisäheiton normeista. Sellaisista sanoista, joista vokaali on heittynyt nominatiivista, se on näet heittynyt myös muista 
taivutusmuodoista, vaikka niissä onkin kolmatta tavua alkamassa soinniton $s$, esim. ihmsen, käümseskän 'käymisessäkään'. Edelleen sisäheitto on tavattavissa myös puolessakymmenessä pronominivartaloisessa nen-loppuisessa sanassa, joissa toisessa tavussa on ollut alkuperäinen diftongi, esim. kumne, mimne, tämne. Näissäkin sanoissa tavataan vokaalien heittymistä myös sekä mon. nominatiivissa että obliikvisijoissa, esim. semsses, semssi jne. (Ojansuu I, 118-119.)

Myös murretekstien tarjoama kuva on tällä kohtaa kirjavahko. Muodot talvinen (Tkola-Wiik, 213:12, Euraj.) ja tuahinen (SKMK, 15, Laitila), ehkä myös erisnimi tammine (Kettunen I, 3:7, Euraj.) osoittavat vokaalin säilyneisyyttä, kun taas muodot ihmne, ihmsek (Ikola-Wiik, 212:3, 202:37, Euraj.), kaikem p äls eks (Kettunen I, 1:4 Euraj.) ja kärejän käy $m n$ e $n$ (SKMK, 18, Pymämaa) samoin kuin sisäheittoisina melko tavalliset pronominivartaloiset muodot, esim. semssi ja tomsse 'tuommoiset' (Ruoppila-Soutkari, 9:19, 9:38, Rauma), todistavat, että sisäheittoa yhä esiintyy myös tässä ryhmässä — ja nimenomaan Ojansuun esittämällä tavalla.

Hahnssonin tutkimusten avulla poikkeusryhmien luetteloa voi vielä vähän jatkaa. Ojansuulta puuttuvat sisäheiton käsittelystä kokonaan seuraavat muotoryhmät.

6. Potentiaalin preesensin muodot. Nämäkin ovat tosin alueella melkoiselta osin nn:llisiä, esim. laolannek, puhunnek, saatannek (ks. esim. Ojansuu II, 150; Hahnsson I, 63), mutta alueen eteläosista Hahnsson on merkinnyt myös seuraavankaltaisia muotoja: (Laitilasta ja Pyhästämaasta) mentänek, syätänek, juatanek, (Lapista Laitilan rajalta) neolonengon. Kuten esimerkit osoittavat, muodot ovat kaikki sisäheitottomia.

7. ve-tunnuksiset komparatiivimuodot. Hahnssonin tutkimuksissa on tähän kuuluvia esimerkkejä useista eri pitäjistä (yhteydestä ei vain käy selvästi ilmi, mikä esimerkki on mistäkin pitäjästä); kaikille niille on tunnusomaista, että ne ovat sisäheitottomia, esim. kylmevemp, kilteve, huanove (Hahnsson II, 326-327).

8. Lisäksi voitaneen - epäsäännöllisyytensä vuoksi tosin vähän kyseenalaisesti — poikkeusryhmiin vielä liittää ne-johtimiset verbit. Hahnssonin maininnan mukaan näissä verbeissä säilyy Eurajoella, Pyhässämaassa ja Laitilassa usein - jos kohta ei poikkeuksettomasti - johdinta edeltävä vokaali, vaikka sisäheiton edellytykset olisivatkin olemassa, esim. aukene, lämpene, vanhene jne. Kuitenkin voidaan 
tavata myös sisäheittoisia aukne, happne, vanhne -muotoja, tällaisia varsinkin Lapissa ja Raumalla. ${ }^{6}$ (Hahnsson I, 22-23.)

Näin esitellyt sisäheittoilmiön piiriin kuuluvat poikkeustapaukset voidaan helposti jakaa kolmeen ryhmään.

a. Verrattaessa poikkeusryhmiä suomen sanojen taivutukseen voidaan tehdä kiintoisa havainto. Esittämäni ryhmät näet sisältävät kaikki ne kielemme niin nominien kuin verbien taivutuksessa esiintyvät muotoryhmät, joissa voi syntyä yleisen sisäheittolain mukaiset edellytykset (ks. sanojen taivutusmalleja esim. teoksesta Setälä, Suomen kielioppi, 17. painos, 73-123). Konjugaatio- ja deklinaatiomuotoihin yhdistyvät lisäksi alueelle tyypilliset komparatiivimuodot (niiden ilmeisen analoginen alkuperä on tämän artikkelin kannalta vähemmän merkityksellinen, ks. Ravila, Über das finnisch-ugrische komparativsuffix, FUF XXIV, 50-52).

Taivutusmuotojen lisäksi poikkeusryhmät sisältävät vielä joukon johdannaisia, jotka voidaan edelleen jakaa kahteen osaan.

b. Osa johdannaisista on erittäin läheisessä suhteessa taivutusmuotoihin. ma, mä- ja minen-johdinhan ovat muodoltaan täysin identtiset vastaavien agenttipartisiipin ja infinitiivien tunnusten kanssa. Mutta myös syntaktisessa suhteessa se raja, jonka toiselle puolen jäävät selvät johdannaisnominit, toiselle taas verbin taivutusmuodot, on erittäin vaikeasti käytävissä. Kaksi muuta edellisissä ryhmissä esiintyvää johdinta - maton, mätön ja vainen, väinen - ovat puolestaan mm. nykyisten infinitiivin ja partisiipin tunnusten pohjalta kehittyneet. Ja lisäksi on syytä huomata myös näillä yhdistetyillä johtimilla muodostettujen sanojen läheinen syntaktinen yhteys infinitiiveihin ja partisiippeihin. vainen, väinen -johdannaiset näet esiintyvät nimenomaan lounaismurteissa hyvin samankaltaisissa teh-

- Tämän lisäksi Hahnsson esittää — eräiden sisäheitottomien yksittäistapausten lisäksi -, että $v a$, vä -loppuisista vartaloista ei toisen tavun vokaali koskaan heity; esimerkkinä hänellä on kuitenkin vain peräti harvinaiset adjektiivit kaolavan' ja niskavan' (Hahnsson I, 19-20). Tämä havainto pitää tuskin kuitenkaan yleisesti paikkaansa. Niinpä esim. Ojansuulla on tutkimuksessaan mm. sisäheittoiset muodot üstväline, sü̈ästvä 'syöstävän', hahtva 'hahtuvat' eikä toisaalta minkäänlaista mainintaa $v a, v \ddot{a}$-loppuisten nominien yleisestä poikkeuksellisuudesta (Ojansuu I, 121). Saattaa olla, että Hahnssonin väite ainakin osittain johtuu esim. $v a$, vä -loppuisten partisiippien sisäheitottomuudesta. 
tävissä kuin va, vä -loppuiset muodot. ${ }^{7}$ Ja maton, mätön -päätteiset karitiiviadjektiivit taas ovat paljolti itse asiassa niin I kuin II partisiipin muotojen kielteisiä vastineita. ${ }^{8}$ Näin siis voidaan todeta, että kaikki nämä neljä johdinta ovat itse asiassa mitä läheisimmin yhteydessä varsinaiseen sanojen taivutukseen; eivätkä mainitut johtimet ole vain muodoltaan (joko kokonaan tai osittain) identtisiä nominaalimuotojen tunnusten kanssa, vaan myös niillä johdettujen sanojen käyttö suuresti muistuttaa taivutusmuotojen käyttöä.

c. Loput kaksi johdannaisryhmää, nimittäin nen-loppuisten nominien ja ne-johtimisten verbien ryhmät, voidaan puolestaan yhdistää keskenään. Molemmat johtimet esiintyvät näet nykykielessä sekaparadigmoissa. Kuten jo edellä olevasta katsauksesta on käynyt ilmi, nen-johdannáinen esiintyy itse asiassa vain yks. nominatiivina; paradigman muut muodot ovat se-johdannaisia. Mutta myös ne-johdin vaihtelee nykyisin taivutuksessa $t$-johtimen $(<n t e)$ kanssa, esim. kalpenee, kalvetkoon. Näin ollen niin nen- kuin ne-johdannaistyyppi ovat itse asiassa sellaisia, että vain niiden eräissä muodoissa on olemassa sisäheiton edellytykset.

Sisäheiton poikkeusilmiötä tarkasteltaessa on säännöllisesti viitattu muotosarjojen yhtenäistävään vaikutukseen (ks. esim. artikkelini alkuosasta Rapolan teoksesta otettua sitaattia). Kuhunkin muotosarjaan kuuluu tietysti myös sellaisia muotoja, joissa ei ole sisäheiton toteutumisen edellytyksiä. Tämän seikan on yleisesti nähty vaikuttavan joko "tasoittavasti" tai "palauttavasti" niin, että sisäheitto ei ilmene myöskään niissä muodoissa, joissa vokaalin heittymiselle olisi olemassa edellytykset.

$\tau$ Niinpä Knut Cannelin ryhmittää eräässä artikkelissaan yhteen I partis:n ja vainen, väinen -loppuiset muodot. (Ks. Cannelin, Kielteisyyden ilmaiseminen suomenkielessä, Vir. 1930, 240.) Siitä, että vainen, väinen -loppuiset muodot ovat nimenomaan lounaismurteissa usein vastaamassa muiden murteiden va, vä -loppuisia muotoja, saattaa osittain johtua, että alkuaan lounaismurteisen kirjakielen murrepohjan vähitellen laajetessa lylyemmät muodot ovat syrjäyttäneet pitempiä (ks. esim. Rapola, Kirjakielemme sananrakenteiden tiivistymisen historiaa, Vir. 1945, 147).

8 Samaa asiaa todistelee em. artikkelissaan myös Cannelin; hän jopa nimittää maton, mätön -loppuisia muotoja nimellä karitiivinen adjektiivi (alias kielteinen partisiippi) (Cannelin, ema., Vir. 1930, 241-242). 
Haluamatta ollenkaan kiistää tämän anologiaselityksen oikeutusta tahtoisin kuitenkin viitata myös eräisiin toisiin näkökohtiin, jotka saattavat nekin olla olennaisia poikkeusmuotojen ymmärtämisen kannalta. Ensinnäkin on syytä huomata, että tasoitus on tapahtunut kaikissa muotoryhmissä samaan suuntaan, ts. ne muodot, jotka olisivat säännön mukaan sisäheittoisia, eivät ole missään ryhmässä päässeet ylivaltaan ja mukauttamaan ryhmää kauttaaltaan sisäheittoiseksi. Toiseksi: kuten edellä on esitetty, sisäheittoedellytykset omistavat kolmi- ja useampitavuiset sanat ovat suhteessaan sisäheittoon jakautuneet ikään kuin kahdeksi suureksi, sisäisesti homogeeniseksi ryhmäksi: sisäheitottomiin taivutusmuotoihin - joihin siis liittyvät varsinaisiin paradigmamuotoihin morfologisesti ja usein myös syntaktisesti erittäin läheisessä suhteessa olevat muodosteet - sekä sisäheittoisiin muihin sanoihin — joita siis ovat joko varhaisemmat tai myöhäisemmät johdannaiset sekä lainasanat.

Nämä seikat johtavat ajatukset myös siihen mahdollisuuteen, että paradigman kokonaisuuden huomioon ottaminen saattaisi myös olla hyödyllistä sisäheittoilmiön poikkeusmuotojen selittämisen vuoksi. Mutta mitä uutta tämä aspekti sitten voisi tarjota?

Tarkastelkaamme, mitä paradigman kannalta olennaista tapahtuisi, jos sisäheitto pääsisi vaikuttamaan myös taivutusmuotoihin. Ainakin yksi seuraus olisi väistämätön: taivutusvartaloiden määrä kasvaisi olennaisesti. Toisaalta näet monet aikaisemmin yksivartaloiset sanat muuttuisivat kaksivartaloisiksi, toisaalta taas monille ennestään kaksivartaloisille sanoille syntyisi epäilemättä uudentyyppinen konsonanttivartalo (esim. juosta-verbin entinen konsonanttivartalo on juos-, mutta jossakin juoksema-muodossa vaikuttava sisäheitto synnyttäisi varmaan vartalon juoks-). Kenties kielisysteemi onkin nyt pyrkinyt systemaattisesti torjumaan tätä sisäheiton mukanaan tuomaa hajaannusta ${ }^{9}$ ja siinä melko hyvin onnistunutkin, jos katsotaan asiaa Ojansuun taikka Hahnssonin aikaisten äännesuhteiden kannal-

${ }^{9}$ Loppuheiton aikaansaama vartaloiden hajaannus ei luultavasti ole paradigman kokonaisuuden kannalta yhtä vaarallista. Loppuvokaalin kato aiheuttaa näet yleensä vain (nominien) perusmuodon etääntymisen muotosarjasta; kuten suomen monet taivutuskaavat osoittavat, saattaa nimenomaan perusmuoto näköjään haitatta etääntyä obliikvisijojen muodoista. 
ta. ${ }^{10}$ Lopultakin näet vain muutamat sekaparadigmat (nen-loppuiset nominit ja ne-johtimiset verbit) olivat kykenemättömiä mukautumaan johdonmukaisesti vallitsevaan järjestelmään. Toisaalta kuitenkin on syytä korostaa, että edellä esitettyjä ajatuksia suorastaan tukevat myös nen-loppuisten muotojen (sinänsä harvinaiset) sisäheittotapaukset: paradigman hallitseva vaikutus näkyy näet selvästi siinä, että mikäli uusi "konsonanttivartalo" kerran on sisäheiton ansiosta syntynyt, se on väkivalloin pyrkinyt yleistymään koko paradigmaan.

Kaiken kaikkiaan olen siis nähdäkseni voinut artikkelissani osoittaa, että Rauman seudun murteen sisäheittoilmiö todistaa poikkeuksineenkin voimakkaasti kielen systeeminluonteen puolesta; ilmiön piiriin kuuluvat poikkeusryhmät eivät ole satunnaisia eivätkä erillisiä, vaan järjestyvät yhteisten tendenssien aikaansaamaksi kiinteäksi kokonaisuudeksi.

${ }^{10}$ On tietenkin kokonaan toinen asia, että sisäheitto — niin kuin monet muutkin murrepiirteet - on nykymurteissa yleisten murteiden tasoittumistendenssien vuoksi käynyt niin epäsäännölliseksi, että esim. käyttämistäni teksteistä olisi ollut äärimmäisen vaikeata erottaa niitä muotoryhmiä, jotka "säännöllisesti" ovat sisäheitottomia. Kuten esimerkeistäni selvästi näkyy, ei sisäheitto kuitenkaan ole myöhemminkään käynyt siinä mielessä horjuvaksi, että se olisi kyennyt yleistymään sellaisiin asemiin, joissa sitä aikaisemmin ei esiintynyt. 


\section{A. Alhonimmi: Über die Synkope im Dialekt der Gegend um Rauma}

Im betreffenden Dialekt hat in der zweiten, ursprïnglich offenen Silbe der wenigstens dreisilbigen. Wörter oftmals ein Vokalschwund stattgefunden vorausgesetzt, dass die erste Silbe lang ist und am Anfang der dritten ein $l, m, n, r$ oder $v$ steht. Es wurde aber schon im 19. Jahrhundert festgestellt, dass es einige Formengruppen gibt, wo die Erscheinung nicht vorkommt. Der Verf. befasst sich mit diesen Fällen und kommt zu dem Schluss, dass der Vokalschwund mit ziemlicher Regelmässigkeit in folgenden Fällen $\mathrm{n}$ i ch t eintritt: 1. Vor den Flexionsendungen der Nomina und Verba. 2. In einigen Ableitungen, deren Form entweder völlig mit gewissen infiniten Formen übereinstimmt oder aus diesen abgeleitet ist; derlei Ableitungen sind in der Regel auch hinsichtlich ihrer Verwendung mit den eigentlichen infiniten Formen verknüpft. 3. Schwanken herrscht bei den Nominalableitungen auf - $(i)$ nen und den Verbalableitungen auf - ne-; beide weisen insofern ein gemischtes Paradigma auf, als bei vielen Biegungsformen die Voraussetzungen für eine Synkope fehlen.

Der Verf. stellt fest, dass alle Worte gevissermassen auf zwei Gruppen entfallen: Flexionsformen ohne Synkope und sonstige Wörter mit Bereitschaft zur Synkope (zu dieser Gruppe gehören die alten und jungen Ableitungen und die Lehnwörter). Als Grund für die Ausnahmeerseheinungen im Bereich der Synkope wird in herkömmlicher Art regelmässig der analogisch anregende Einfluss der synkopenfreien Formenreihen erwähnt. Der Verf. aber vermutet, dass auch die übrigen Formen des Paradigmas - also das Paradigma als Ganzes - vereinheitlichend und synkopenhindernd gewirkt hat. 